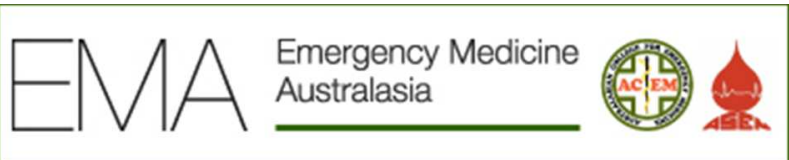

\title{
Emergency Department Models of Care in the context of Care Quality and Cost: a Systematic Review
}

\begin{tabular}{|c|c|}
\hline Journal: & Emergency Medicine Australasia \\
\hline Manuscript ID: & Draft \\
\hline Manuscript Type: & Review Article \\
\hline Date Submitted by the Author: & $\mathrm{n} / \mathrm{a}$ \\
\hline Complete List of Authors: & $\begin{array}{l}\text { Wylie, Kate; Queensland University of Technology, School of Public Health } \\
\text { and Social Work } \\
\text { Crilly, Julia; Griffith University, Griffith Health Institute } \\
\text { Toloo, Ghasem (Sam); Queensland University of Technology, School of } \\
\text { Public Health and Social Work } \\
\text { FitzGerald, Gerry; Queensland University of Technology, School of Public } \\
\text { Health and Social Work } \\
\text { Burke, John; Royal Brisbane and Women's Hospital, Department of } \\
\text { Emergency Medicine } \\
\text { Williams, Ged; Griffith University, Griffith Health Institute } \\
\text { Bell, Anthony; QE II Jubilee Hospital, Department of Emergency Medicine }\end{array}$ \\
\hline Keywords: & Emergency Department, Models of Care, Value, Quality , Cost \\
\hline Abstract: & $\begin{array}{l}\text { Study Objective: To identify current ED models of care and their impact on } \\
\text { care quality, care effectiveness, and cost. } \\
\text { Methods: A systematic search of key health databases (Medline, CINAHL, } \\
\text { Cochrane, EMbase) was conducted to identify literature on Emergency } \\
\text { Department (ED) models of care. Additionally, a focussed review of the } \\
\text { contents of } 11 \text { international and national emergency medicine, nursing and } \\
\text { health economic journals (published between } 2010 \text { and } 2013 \text { ) was } \\
\text { undertaken with snowball identification of references of the most recent } \\
\text { and relevant papers. Articles published between } 1998 \text { and } 2013 \text { in the } \\
\text { English language were included for initial review by three of the authors. } \\
\text { Studies in underdeveloped countries and not addressing the objectives of } \\
\text { this study were excluded. Relevant details were extracted from the } \\
\text { retrieved literature, and analysed for relevance and impact. The literature } \\
\text { was synthesised around the study's main themes. } \\
\text { Results: Models described within the literature mainly focused on } \\
\text { addressing issues at the input, throughput or output stages of ED care } \\
\text { delivery. Models often varied to account for site specific characteristics } \\
\text { (e.g. onsite inpatient units) or to suit staffing profiles (e.g. extended scope } \\
\text { physiotherapist), ED geographical location (e.g. metropolitan or rural site), } \\
\text { and patient demographic profile (e.g. paediatrics, older persons, ethnicity). } \\
\text { Only a few studies conducted cost effective analysis of service models. } \\
\text { Conclusion: Whilst various models of delivering emergency health care } \\
\text { exist, further research is required in order to make accurate and reliable } \\
\text { assessments of their safety, clinical effectiveness and cost effectiveness. }\end{array}$ \\
\hline
\end{tabular}




\section{Page 1 of 21}

Under review process

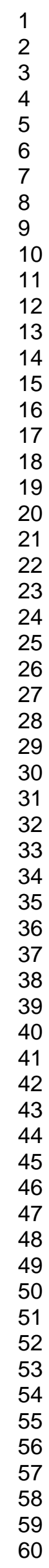

SCHOLARONE ${ }^{\text {m }}$ Manuscripts

10

11

13

14

15

16

18

19

20

22

23

25

26

27

29

32

33

34

36

37

40

41

42

44

45

46

47

48

49

51

52

53

54

56

57

58

60

Under review process 
Title: Emergency Department Models of Care in the context of Care Quality and Cost: a Systematic Review

Running Head: ED Models of care, Quality and Cost

\section{Authors}

Kate Wylie ${ }^{1}$ Julia Crilly ${ }^{2,3}$ Ghasem (Sam) Toloo ${ }^{1}$ Gerry FitzGerald ${ }^{1}$ John Burke $^{4}$ Ged Williams ${ }^{2,3}$ Anthony Bell ${ }^{5,6,7}$

\section{Authors' affiliations}

1. Queensland University of Technology, Brisbane, Queensland, Australia

2. Gold Coast Hospital and Health Service, Gold Coast, Queensland, Australia

3. Griffith Health Institute, Griffith University, Gold Coast, Queensland, Australia

4. Royal Brisbane and Women's Hospital, Brisbane, Queensland, Australia

5. Queen Elizabeth II Hospital, Brisbane, Queensland, Australia

6. Clinical Access and Redesign Unit, Brisbane, Queensland, Australia

7. University of Queensland School of Medicine, Brisbane, Queensland, Australia

\section{Corresponding Author}

Associate Professor Anthony Bell

QEII Hospital Emergency Department, Troughton Road, Coopers Plains, Qld 4108

\section{Acknowledgements}

The authors would like to acknowledge and thank the following organisations for their generous funding and support: Queensland Emergency Medicine Research Foundation (QEMRF) for funding; Centre for Emergency and Disaster Management (CEDM), Queensland University of Technology (QUT); The University of Queensland (UQ); Griffith University; Queensland Government Department of Health; Australian-American Fulbright Commission. 


\title{
Title: Emergency Department Models of Care in the context of Care Quality and Cost: a
} Systematic Review

\begin{abstract}
Study Objective: To identify current ED models of care and their impact on care quality, care effectiveness, and cost.

Methods: A systematic search of key health databases (Medline, CINAHL, Cochrane, EMbase) was conducted to identify literature on Emergency Department (ED) models of care. Additionally, a focussed review of the contents of 11 international and national emergency medicine, nursing and health economic journals (published between 2010 and 2013) was undertaken with snowball identification of references of the most recent and relevant papers. Articles published between 1998 and 2013 in the English language were included for initial review by three of the authors. Studies in underdeveloped countries and not addressing the objectives of this study were excluded. Relevant details were extracted from the retrieved literature, and analysed for relevance and impact. The literature was synthesised around the study's main themes.
\end{abstract}

Results: Models described within the literature mainly focused on addressing issues at the input, throughput or output stages of ED care delivery. Models often varied to account for site specific characteristics (e.g. onsite inpatient units) or to suit staffing profiles (e.g. extended scope physiotherapist), ED geographical location (e.g. metropolitan or rural site), and patient demographic profile (e.g. paediatrics, older persons, ethnicity). Only a few studies conducted cost effective analysis of service models.

Conclusion: Whilst various models of delivering emergency health care exist, further research is required in order to make accurate and reliable assessments of their safety, clinical effectiveness and cost effectiveness.

Keywords: Emergency Department, Models of Care, Quality, Cost 


\section{INTRODUCTION}

Demand is growing in emergency healthcare systems (EHS) around the world that are already overburdened and facing rising costs of care, deteriorating performance standards and overcrowding as represented by access block and ambulance diversion. ${ }^{1}$ These factors fragment and threaten the quality of care patients receive and is neither desirable nor sustainable. ${ }^{1,2}$ Complexity of care is also increasing, as patients survive longer with severe chronic diseases that are now better able to be managed due to enhancements in health technology and evidence based practices. Infrastructure (particularly hospital beds) is proportionately less than demand requires, leading to rationing of services and blocked access of patients requiring admission. ${ }^{3}$

In terms of its contribution to hospital efficiency, the key function of an ED is to i) evaluate, ii) treat and iii) discharge or admit patients where appropriate. A variety of models of care have been implemented within EDs that seek to improve one or more of these functions. Examples include: fast track areas for patients with minor injuries, ${ }^{4-6}$ observation wards for patients requiring $<24$ hours admission, ${ }^{7,8}$ rapid assessment teams, ${ }^{9}$ nurse practitioners, ${ }^{10}$ and various full or extended scope allied health models; more common now since the introduction of time based targets for emergency care in countries including the UK (4 hours), ${ }^{11}$ New Zealand (6 hours), ${ }^{12}$ and, more recently, in Australia (4 hours). ${ }^{13}$ Activity based funding (ABF) has refocussed efforts to ensure effective systems of care within an efficient economic operating environment.

Previous literature reviews have examined the relationship between ED crowding and poor performance on time related clinical measures or ED crowding and patient outcomes. ${ }^{14,15}$ This paper aims to review ED models of care in the context of care quality/effectiveness and cost. It is drawn from a broader systematic review on the implications of ABF for EDs. ${ }^{16}$ 


\section{METHODS}

A systematic search of key health databases was conducted to identify literature in the English language on Emergency Department (ED) models of care. Table 1 presents an overview of the search strategy components including inclusion and exclusion criteria and assessment and synthesis of articles.

\section{RESULTS}

Results from the systematic search are presented in Figure 1. This process resulted in 66 relevant articles for inclusion to inform this review. Asplin et $\mathrm{al}^{17}$ identify three distinct phases within the emergency care pathway: input, throughput and output. These provide the framework for our results and discussion.

\section{Trends in managing Input}

With the worldwide trend of increased demand for ED services, there is considerable debate regarding the cost of providing care. Emergency care expenditure accounts for $2 \%-10 \%$ of the entire health care budget in the US. ${ }^{18}$ The extent of expenditure, coupled with concerns that congestion is causing adverse patient outcomes has resulted in both legislated and research efforts to reduce ED input. ${ }^{19}$

In the USA, reducing the number of uninsured Americans, the introduction of accountable care organisations, ${ }^{20}$ specialty EDs and regionalisation of EDs are anticipated to transform demand, the type of patients accessing EDs and their operational efficiency. ${ }^{21}$ Carecoordination has been one response in this system to improve information flows and continuity. It is believed that there will be a resultant reduction in readmissions and ED presentations, ${ }^{20}$ with improved quality but the evidence is not yet out. 
Healthcare reforms in Canada, the UK and Australia include investment in health prevention and primary care. Efforts include incentivising medical students to enter primary care to reduce skills shortages, building General Practitioner (GP) super clinics, upgrading existing health care infrastructure and the introduction of after hour GP responsibilities. ${ }^{19,22}$ Mixed opinions have been documented regarding these strategies with some experts suggesting a greater investment is required to improve and maintain these systems than is required to cover the cost of increasing ED demand, ${ }^{23}$ which is difficult to accurately cost.

Alternative models of care to reduce ED input have been investigated in the UK. Observational evaluations show the benefits of a "treat and discharge" service provided by Emergency Care Practitioners (ECP) via the ambulance service. Preliminary results suggest that treatment plans provided by ECPs were consistent with those provided by an Emergency Medical Officer, with the added benefit of making the assessment at home, reducing presentations to ED. ${ }^{22,24}$ Other demand management strategies included the establishment of minor injury units (MIU) as conduits to $\mathrm{EDs},{ }^{25,}{ }^{26}$ telephone triage systems, ${ }^{27}$ and walk-in centres. ${ }^{10}$ There was a noticeable absence of the cost benefit of these models within the literature.

Outside of the healthcare system, the literature indicates that US businesses are gaining the support of private insurers to employ a health professional onsite to assess and treat employees rather than paying the insurance overheads that occur as a result of receiving primary or emergency care. For example, employing and resourcing an acute care nurse practitioner full-time is up to 16 times more affordable $(\$ 82,000$ cost of nurse: $\$ 1,313,756$ paid on health overheads before nurse) than paying expensive insurance excesses. ${ }^{10}$ This model of care may have implications on the utilisation rate of EDs if it becomes more mainstream. 
Regardless of all health reform attempts to reduce ED input, it is suggested that growth in demand is only part of the explanation for ED congestion. ${ }^{23,28}$ Therefore, impediments to ED throughput and outflow also require consideration. ${ }^{19}$

\section{Trends in managing Throughput}

Studies show that demand for and access to EDs are addressed at a strategic government level, whereas throughput efficiencies are being addressed at a local operational level. Callander and Schofield ${ }^{29}$ evaluated innovative operational and workforce models of care within EDs but note that further research is required to better understand how and which models to implement.

\section{Workforce Models of Care}

According to Paw, ${ }^{30}$ an appropriate level of staffing is the single most important factor in providing prompt, timely and clinically effective patient care within an emergency care setting. Factors such as volume, acuity, historic patterns of demand and patient expectations need to be considered in the development of staffing models, all while keeping costeffectiveness a priority.

The most prevalent model evaluated within the literature is the Emergency Nurse Practitioner (ENP) role. Despite slight role variations across nations, ENPs generally assume the responsibility for patients presenting with minor injuries or illnesses, and operate within throughput management systems such as Fast-Track and See-and-Treat. ${ }^{31-34}$ Studies on ENP models of care consistently report reduced waiting times (WT) ${ }^{35-37}$ and length of stay (LOS) ${ }^{34 \text {, }}$ ${ }^{38}$ for lower acuity patients, and increased patient satisfaction. ${ }^{26,}{ }^{39}$ Evidence also suggests ENPs offer improved quality of care (reduced errors causing adverse events, lower unplanned re-presentation rates), improved continuity of care, ${ }^{35}$ and less staff turnover when compared to Senior House Officers (SHOs). ${ }^{26,34,40}$ Two opposing opinions, but no cost benefit analyses, 
exist regarding the value of ENPs. One common theory is that the ENP role is cost inefficient (i.e. high salary, regulated hours of work) when compared to SHOs. ${ }^{26}$ The opposing view is that the reduced training costs from lower turnover offsets the salary consideration and lower representation and adverse event rates provide improved value for patients ${ }^{25,26}$

To improve LOS, the presence of additional medical officers has been trialled. ${ }^{41-46}$ While, outcomes suggest that additional staff improves throughput targets for the discharging of patients, they do not significantly improve the overall LOS as the role is not able to influence admitted patient's timeframes. ${ }^{41,46}$ The presence of an emergency physician (EP) in triage produces similar outcomes with the additional benefit of a potential reduction in ambulance diversions. ${ }^{43-45}$ Another study examining the benefits of 24-hour consultant or senior level coverage reported increased efficiencies in triage, diagnostics, patient flow and admission. ${ }^{47}$ A cost-effectiveness analysis is required for the models referred to above to determine if additional input costs result in a return on investment in terms of quality or other realised benefits.

Literature on models of care using support staff (e.g. physician assistants and ED scribes) suggests there may be some benefit to ED flow and efficiency. ${ }^{48}$ Allied Health Practitioners in referral models within EDs do little to improve congestion but value add; for example, clinical pharmacists within the ED reduce the number of medication errors and resulting adverse events, ${ }^{49,50}$ and radiographer-led radiology services may reduce interpretive errors. ${ }^{51}$ A systematic review inferred that in some studies Care Coordination Teams were effective in reducing unnecessary social admissions in elderly populations and significantly reduced representations. ${ }^{52}$ Finally, one qualitative study revealed that the presence of allied health appeared to contribute positively towards team unity, staff satisfaction and retention rates. ${ }^{53}$ It is inferred in these models that a cost benefit exists (e.g. fewer adverse events, less representations and improved clinical outcomes) but never is it quantified. 


\section{Operational Models of Care}

Many innovative operational models of care have been trialled to assist with minimising ED throughput inefficiencies. Fast-Track systems are useful models of care for dealing with a

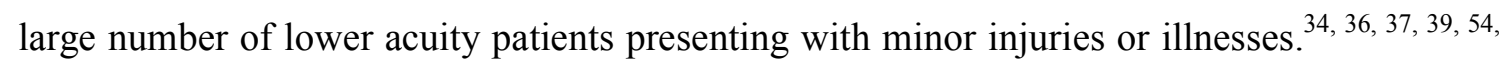
55 Also known as Ambulatory areas, See-and-Treat Services, Minor-Injury-Units and RapidIntervention-and-Treatment-Zones they typically operate over hours convenient to negotiated workforce agreements rather than consumer demand and are staffed by a varying mix of medical officers and ENPs. ${ }^{36,37,39,54,55}$ Patients benefit from improved flow and continuity of care, are generally satisfied and have shorter WT and LOS during the hours of operation. ${ }^{34,36 \text {, }}$ ${ }^{37}$ There is a paucity of evidence regarding the cost effectiveness, however several studies do suggest that an outpatient clinic alternative would incur far greater financial costs. ${ }^{23,36,39,54}$

An Australian study ${ }^{56}$ demonstrated the effectiveness of a unique model titled "Senior Streaming Assessment Further Evaluation after Triage Zone" (SAFE-T zone). Similar to Fast Track models the SAFE-T zone operated over a restricted daily schedule but in this case required additional staff and attendant costs. All presentations, with the exception of those requiring resuscitation, were seen and triaged on arrival by a senior medical officer, $\mathrm{SHO}$, or registered nurse. This enabled them to be transferred to an early treatment zone to commence intervention or to Fast-Track for urgent management and discharge. Acute care beds were quarantined for high acuity patients or to be made available at times of surge capacity. Offstretcher times and ambulance diversion rates also improved. ${ }^{56}$

"Quick Diagnostic Units" (QDU) have been introduced in Spain to manage referrals from GPs to EDs arising from inaccessible outpatient diagnostic services. ${ }^{57}$ QDUs, staffed by Internal Medicine Specialists, were effective at reducing the ED LOS due to reduced unnecessary ED admissions. ${ }^{57}$ The application of this model in other countries is as yet untested as far as we are aware. 
Other models with a similar underpinning intention of QDUs involving rapid throughput have been implemented in Australia. These include Clinical Decision Units, ${ }^{58-60}$ Medical Assessment and Planning Units (MAPU), ${ }^{61}$ Rapid Assessment and Planning Units, Observation bays, Express Admission Units (EAU), ${ }^{59,62}$ the use of non-traditional beds,${ }^{63}$ and opening new (additional) or available (but previously unstaffed) beds within the ED. ${ }^{60}$ Generally findings suggest that additional infrastructure and corresponding staffing can impact positively on some but not all throughput efficiencies and the sustainability of positive outcomes appears time limited. ${ }^{60}$ These models require further exploration and evaluation to determine which model and staffing profile can result in the most efficacious and safe service and the optimal configuration.

\section{Trends in managing Output}

Asplin et $\mathrm{al}^{17}$ suggest that ED output is the ability to move patients out of ED into inpatient bed or onto an appropriate outpatient follow-up schedule. The inability to do this causes ED outflow obstruction ${ }^{64}$ and is typically a result of lack of physical beds, poor accessibility to available inpatient beds due to inflexible systems or protocols, isolation precautions, cleaning delays, over reliance on Intensive Care Units / High Dependency Units beds, inefficient diagnostics or delays in discharging hospitalised patients to post-acute facilities. ${ }^{17}$ With the focus of this review being on ED models of care and economic analyses accounting for ED activity, this literature search did not specifically retrieve articles on the outcomes associated with output efficiencies.

\section{DISCUSSION}

Using Asplin's model, ${ }^{17}$ our review identified major trends and issues in models of care at the input, throughput and output stages of ED service delivery. On the demand side, there are a complex set of relationships at play between population growth, changing demographics and 
access to primary care. Demand for ED services is driven by 24 hour access with ever expanding service capability and practitioner type and timely diagnostics within systems that are continually redefining the patient journey.

As such, there is incredible variation in how EDs currently value their available resources in respect of the models of care they implement to achieve throughput and ultimately the correct disposition for patients. There is the potential for the reduced reimbursement for general practitioners and improved performance against time based targets having the unintended consequence of driving rather than mitigating ED demand. The role of specialised EDs (e.g. for trauma, paediatrics, mental health or older persons) warrant consideration and formal evaluation.

Following the move to ABF within Australian EDs, the initial outcomes of ABF resourcing are slowly being realised. Particular consideration for how teaching/training costs and other overheads are accounted for in budgets is necessary. A bottom up cost profiling of ED activity that would allow an Urgency Related Grouping (URG) cost reconciliation ${ }^{65}$ may provide an initial framework for this process. Cost-effective measures of performance that can be shown to improve efficiency need to be clearly identified and supported for implementation.

Research into the fee for service financial arrangements, in private Australian EDs, and patient outcome measures is required to see if those models, with a predominant specialist emphasis, could confer benefits within public EDs funded under ABF. Finally, further research into the size effect (i.e. treatment spaces and presentations) on optimal ED functioning, clinician productivity and quality indicators is required. Research into optimal ED size is required to understand the relationship between economies of scale and economies of distance between EDs in the same geographical region. 
Patient flow focussed clinical redesign efforts provide practitioners and hospital executives a framework of local and systemic understanding of the impediments to early discharge of admitted patients to ward areas. However, detailed cost-effectiveness analyses are unavailable. Furthermore, when time-based targets represent stretch targets, and additional resources are allocated, there is a paucity of evidence that defines the opportunity cost for other service lines. Clinical outcome data has been missing from the value equation to date and will inform the optimal point at which time based targets need to be balanced against the additional resources needed to achieve them. Finally, research that considers the financial contribution that patients admitted via an ED, to Short Stay Units or ward areas, have on hospital revenue in the Australian context is required.

\section{CONCLUSION}

We suggest that ED researchers in this area should engage in cost-benefit analysis in order to produce credible research that demonstrates cost effectiveness of staff mix and ED models of care within a time driven quality framework. Such analysis would be unique and valuable, whether it is performed in an $\mathrm{ABF}$ environment or a population-based funding environment. in order to make accurate and reliable assessments that pertain to safety, clinical effectiveness and cost effectiveness. 


\section{References:}

1. FitzGerald G, Ashby R. National health and hospital network for Australia's future: Implications for emergency medicine. Emerg Med Australas. 2010;22:384-90.

2. Institute of Medicine Committee on the Future of Emergency Care in the US Health System. Hospital-based emergency care: at the breaking point. National Academy of Science, Washington, DC; 2006 [accessed 11/11/2014]; Available from: http://www.nap.edu/catalog.php?record_id=11621.

3. Wilson A, FitzGerald GJ, Mahon S. Hospital beds: A primer for counting and comparing. Med J Aust. 2010;193:302-4.

4. Rodi SW, Grau MV, Orsini CM. Evaluation of a Fast Track Unit: Alignment of Resources and Demand Results in Improved Satisfaction and Decreased Length of Stay for Emergency Department Patients. Quality Management in Healthcare. 2006;15(3):163-70.

5. O'Brien D, Williams A, Blondell K, Jelinek GA. Impact of streaming "fast track" emergency department patients. Aust Health Rev. 2006;30(4):525-32.

6. Kwa P, Blake D. Fast track: Has it changed patient care in the emergency department? Emerg Med Australas. 2008;20(1):10-5.

7. Iannone P, Lenzi T. Effectiveness of a multipurpose observation unit: before and after study. Emerg Med J. 2009 June 1, 2009;26(6):407-14.

8. Bullard MJ, Villa-Roel C, Guo X, Holroyd BR, Innes G, Schull MJ, et al. The role of a rapid assessment zone/pod on reducing overcrowding in emergency departments: a systematic review. Emerg Med J. 2012 May 1, 2012;29(5):372-8.

9. Grant S, Spain D, Green D. Rapid assessment team reduces waiting time. Emerg Med. 1999;11(2):72-7. 
10. Chenoweth D, Martin N, Pankowski J, Raymond LW. A Benefit-Cost Analysis of a Worksite Nurse Practitioner Program: First Impressions. J Occup Environ Med. 2005;47(11):1110-6 10.097/01.jom.0000182093.48440.4c.

11. Letham K, Gray A. The four-hour target in the NHS emergency departments: a critical comment. Emergencias. 2012;24(1).

12. Ministry of Health New Zealand. Emergency departments. New Zealand Government; 2014 [updated 23/6/2014; accessed 11/11/2014]; Available from:

http://www.health.govt.nz/our-work/hospitals-and-specialist-care/emergencydepartments.

13. Geelhoed GC, de Klerk NH. Emergency department overcrowding, mortality and the 4-hour rule in Western Australia. Med J Aust. 2012;196(2):122-6.

14. Johnson KD, Winkelman C. The effect of emergency department crowding on patient outcomes: a literature review. Adv Emerg Nurs J. 2011;33(1):39-54.

15. Bernstein SL, Aronsky D, Duseja R, Epstein S, Handel D, Hwang U, et al. The effect of emergency department crowding on clinically oriented outcomes. Acad Emerg Med. 2009;16(1):1-10.

16. Wylie K, Bell A, FitzGerald GJ, Crilly J, Toloo GS, Burke J, et al. The Implications of Activity Based Funding for Emergency Departments: A Comprehensive Literature Review: Queensland University of Technology; 2014.

17. Asplin BR, Magid DJ, Rhodes KV, Solberg LI, Lurie N, Camargo Jr CA. A conceptual model of emergency department crowding. Ann Emergency Med. 2003;42(2):173-80.

18. Lee MH, Schuur JD, Zink BJ. Owning the cost of emergency medicine: beyond 2\%. Ann Emergency Med. 2013;62(5):498-505. e3. 
19. Rabin E, Kocher K, McClelland M, Pines J, Hwang U, Rathlev N, et al. Solutions to emergency department 'boarding'and crowding are underused and may need to be legislated. Health Aff. 2012;31(8):1757-66.

20. Berger E. Emergency Physicians Face Uncertainty in Accountable Care Organizations: Health Care Megatrend Brings Threats, Opportunities for Emergency Medicine. Ann Emergency Med. 2011;57(4):A13-A5.

21. Schneider SM, Gardner AF, Weiss LD, Wood JP, Ybarra M, Beck DM, et al. The future of emergency medicine. Acad Emerg Med. 2010;17(9):998-1003.

22. Bell D, Mason S. Secondary care and changing the face of emergency care. Emerg Med J. 2010;27(3):189-90.

23. Smulowitz PB, Honigman L, Landon BE. A novel approach to identifying targets for cost reduction in the emergency department. Ann Emergency Med. 2013;61(3):293300.

24. Coates D, Rawstorne S, Benger J. Can emergency care practitioners differentiate between an avoided emergency department attendance and an avoided admission? Emerg Med J. 2012;29(10):838-41.

25. Sakr M, Angus J, Perrin J, Nixon C, Nichol J, Wardrope J. Care of minor injuries by emergency nurse practitioners or junior doctors: a randomised controlled trial. The Lancet. 1999;354(9187):1321-6.

26. Beales J. Innovation in accident and emergency management: establishing a nurse practitioner-run minor injuries/primary care unit. Accid Emerg Nurs. 1997;5(2):71-5.

27. Fry MM. A systematic review of the impact of afterhours care models on emergency departments, ambulance and general practice services. Australasian Emergency Nursing Journal. 2011;14(4):217-25. 
28. FitzGerald G, Toloo S, Rego J, Ting J, Aitken P, Tippett V. Demand for public hospital emergency department services in Australia: 2000-2001 to 2009-2010. Emerg Med Australas. 2012;24(1):72-8.

29. Callander EJ, Schofield DJ. Emergency Department Workforce Models: What the literature can tell us. Emerg Med Australas. 2011;23(1):84-94.

30. Paw R. Emergency department staffing in England and Wales, April 2007. Emerg Med J. 2008;25(7):420-3.

31. O'Connell TJ, Bassham JE, Bishop RO, Clarke CW, Hullick CJ, King DL, et al. Clinical process redesign for unplanned arrivals in hospitals. Med J Aust. 2008;188(6):S18.

32. Lutze M, Ratchford A, Fry M. A review of the Transitional Emergency Nurse Practitioner. Australasian Emergency Nursing Journal. 2011;14(4):226-31.

33. Higginson I, Whyatt J, Silvester K. Demand and capacity planning in the emergency department: how to do it. Emerg Med J. 2011;28(2):128-35.

34. Fry M, Fong J, Asha S, Arendts G. A 12-month evaluation of the impact of Transitional Emergency Nurse Practitioners in one metropolitan Emergency Department. Australasian Emergency Nursing Journal. 2011;14(1):4-8.

35. Bache J. Establishing an emergency nurse practitioner service. Emerg Med J. 2001;18(3):186-9.

36. Cooper MA, Lindsay GM, Kinn S, Swann IJ. Evaluating emergency nurse practitioner services: a randomized controlled trial. J Adv Nursing. 2002;40(6):721-30.

37. Carter AJ, Chochinov AH. A systematic review of the impact of nurse practitioners on cost, quality of care, satisfaction and wait times in the emergency department. Canadian Journal of Emergency Medicine. 2007;9(4):286. 
38. Wilson K, Cameron P, Jennings N. Emergency nurse practitioners: an underestimated addition to the emergency care team. Emerg Med Australas. 2008;20(6):453-5.

39. Dinh M, Walker A, Parameswaran A, Enright N. Evaluating the quality of care delivered by an emergency department fast track unit with both nurse practitioners and doctors. Australasian Emergency Nursing Journal. 2012;15(4):188-94.

40. Fotheringham D, Dickie S, Cooper M. The evolution of the role of the Emergency Nurse Practitioner in Scotland: a longitudinal study. J Clin Nursing. 2011;20(19-20):2958-67.

41. Wu K-H, Chen I, Li C-J, Li W-C, Lee W-H. The influence of physician seniority on disparities of admit/discharge decision making for ED patients. The American Journal of Emergency Medicine. 2012;30(8):1555-60.

42. Vukmir RB, Howell RN. Emergency medicine provider efficiency: the learning curve, equilibration and point of diminishing returns. Emerg Med J. 2010;27(12):916-20.

43. Terris J, Leman P, O’Connor N, Wood R. Making an IMPACT on emergency department flow: improving patient processing assisted by consultant at triage. Emerg Med J. 2004;21(5):537-41.

44. Soremekun OA, Biddinger PD, White BA, Sinclair JR, Chang Y, Carignan SB, et al. Operational and financial impact of physician screening in the ED. The American Journal of Emergency Medicine. 2012;30(4):532-9.

45. Han JH, France DJ, Levin SR, Jones ID, Storrow AB, Aronsky D. The effect of physician triage on emergency department length of stay. The Journal of Emergency Medicine. 2010;39(2):227-33. 
46. Goodacre S, Mason S, Kersh R, Webster A, Samaniego N, Morris F. Can additional experienced staff reduce emergency medical admissions? Emerg Med J. 2004;21(1):51-3.

47. Cooke M, Kelly C, Khattab A, Lendrum K, Morrell R, Rubython E. Accident and emergency 24 hour senior cover--a necessity or a luxury? J Accid Emerg Med. $1998 ; 15(3): 181$.

48. Doan Q, Sabhaney V, Kissoon N, Sheps S, Singer J. A systematic review: The role and impact of the physician assistant in the emergency department. Emerg Med Australas. 2011 Feb;23(1):7-15.

49. Szczesiul JM, Fairbanks RJ, Hildebrand JM, Hays DP, Shah MN. Survey of physicians regarding clinical pharmacy services in academic emergency departments. Am J Health Syst Pharm. 2009;66(6):576-9.

50. Rudis MI, Attwood RJ. Emergency medicine pharmacy practice. J Pharm Pract. 2011;24(2):135-45.

51. Hardy M, Hutton J, Snaith B. Is a radiographer led immediate reporting service for emergency department referrals a cost effective initiative? Radiography. $2013 ; 19(1): 23-7$.

52. Katz EB, Carrier ER, Umscheid CA, Pines JM. Comparative effectiveness of care coordination interventions in the emergency department: a systematic review. Ann Emergency Med. 2012;60(1):12-23. e1.

53. Hendriksen H, Harrison RA. Occupational therapy in accident and emergency departments: a randomized controlled trial. J Adv Nursing. 2001;36(6):727-32. 
54. Considine J, Lucas E, Martin R, Stergiou HE, Kropman M, Chiu H. Rapid intervention and treatment zone: redesigning nursing services to meet increasing emergency department demand. Int J Nurs Pract. 2012;18(1):60-7.

55. Bucheli B, Martina B. Reduced length of stay in medical emergency department patients: a prospective controlled study on emergency physician staffing. Eur J Emerg Med. 2004;11(1):29-34.

56. Shetty A, Gunja N, Byth K, Vukasovic M. Senior streaming assessment further evaluation after Triage zone: a novel model of care encompassing various emergency department throughput measures. Emerg Med Australas. 2012;24(4):374-82.

57. Bosch X, Jordán A, López-Soto A. Quick diagnosis units: avoiding referrals from primary care to the ED and hospitalizations. The American Journal of Emergency Medicine. 2013;31(1):114-23.

58. Schull MJ, Vermeulen MJ, Stukel TA, Guttmann A, Leaver CA, Rowe BH, et al. Evaluating the effect of clinical decision units on patient flow in seven Canadian emergency departments. Acad Emerg Med. 2012;19(7):828-36.

59. Ross MA, Naylor S, Compton S, Gibb KA, Wilson AG. Maximizing use of the emergency department observation unit: a novel hybrid design. Ann Emergency Med. 2001;37(3):267-74.

60. Morris ZS, Boyle A, Beniuk K, Robinson S. Emergency department crowding: towards an agenda for evidence-based intervention. Emerg Med J. 2012;29(6):460-6.

61. Brand CA, Kennedy MP, King-Kallimanis BL, Williams G, Bain CA, Russell DM. Evaluation of the impact of implementation of a Medical Assessment and Planning Unit on length of stay. Aust Health Rev. 2010;34(3):334-9. 
62. Buckley BJ, Castillo EM, Killeen JP, Guss DA, Chan TC. Impact of an express admit unit on emergency department length of stay. The Journal of Emergency Medicine. 2010;39(5):669-73.

63. McNaughton C, Self WH, Jones ID, Arbogast PG, Chen N, Dittus RS, et al. ED crowding and the use of nontraditional beds. The American Journal of Emergency Medicine. 2012 Oct;30(8):1474-80.

64. ACEP. Emergency Department Crowding: High-Impact Solutions. American College of Emergency Physicians; 2008 [acessed 11/11/2014]; Available from: http://www.acep.org/workarea/DownloadAsset.aspx?id=50026.

65. Gedmintas A, Bost N, Keijzers G, Green D, Lind J. Emergency care workload units: A novel tool to compare emergency department activity. Emerg Med Australas. 2010;22(5):442-8. 
Well designed, from reputable sources and contributed by experts in the field relevance, impact and significance

\begin{tabular}{|l|l|}
\hline $\begin{array}{l}456 \text { articles } \\
\text { produced in } \\
\text { total }\end{array}$ \\
$\begin{array}{l}\text { Reviewed for } \\
\text { inclusion by four of } \\
\text { the authors }\end{array}$ & $\begin{array}{l}\text { Synthesised into } \\
\text { main themes in } \\
\text { order to draw } \\
\text { meaningful } \\
\text { review } \\
\text { conclusions }\end{array}$ \\
\hline forticles
\end{tabular}

x 300 DPI 